\title{
A comparative study of automated blood pressure recorders
}

\author{
Peter Rubin \\ D.M., M.R.C.P.
}

\author{
KathleEN McLeAN \\ B.Sc., S.R.N.
}

\author{
JOHN REID \\ D.M., F.R.C.P. \\ University Department of Materia Medica, \\ Stobhill General Hospital, Glasgow G21 3UW
}

\begin{abstract}
Summary and Conclusions
Four automated blood pressure machines (Arteriosonde 1225, Bosomat 11D, Elag Koln BE 237R and Omron HEM 3) have been compared with each other and with the Hawksley Random Zero Sphygmomanometer in 18 subjects with a wide range of BP. Each form of measurement provided a high degree of internal consistency. The Arteriosonde 1225 consistently recorded systolic and diastolic pressures which were below the values obtained with the Random Zero instrument $(P=0.001)$. The other 3 automated machines recorded BPs which did not differ significantly from the Random Zero or from each other. Heart rate readings did not differ significantly for any of the machines compared to manual recording. The disparity attributable to the Arterisonde could result from its being the only form of measurement to use an ultrasonic rather than a microphonic recording technique. However, the cheaper and more portable automated machines produce results which closely reflect those obtained by using a mercury sphygmomanometer.
\end{abstract}

\section{Introduction}

The use of automated BP recorders provides potential advantages in 2 general areas. First, such machines contribute objectivity to a situation in which subjectivity, particularly digit preference and observer bias, is extremely common. Second, they free the physician, nurse or investigator to perform tasks concurrently with the BP being measured. These advantages have led to widespread use of automatic or semi-automatic BP recorders in clinical practice, particularly intensive care, and in research. In consequence there is now available a considerable number of these machines offering a wide range of technical capability and demonstrating an equally wide range of price. There has been no formal comparison of currently marketed automatic BP recorders with each other or with a standard form of BP measurement. This study compares 4 machines which are representative of the current range in terms of price and technical capability.

\section{Subjects and methods}

Four automatic or semi-automatic machines were studied: Arteriosonde 1225 (Electromedical Systems, (Scotland) Ltd, Whins of Milton, Stirling FK7 8ES), Bosomat 11D, Elag Koln BE 237R and Omron HEM 3 (all supplied by Andrew Stephens (1947) and Co., 41 Dickson Road, Blackpool FY12 AP). The Arteriosonde 1225 uses an ultrasonic method of recording while the other 3 automated machines employ microphonic detection. The standard against which these machines were compared was the Hawksley Random Zero Mercury Sphygmomanometer (Hawksley, London).

Eighteen subjects were involved in the study, 13 with high BP and 5 who were normotensive. In all cases the BP was determined with the subjects resting quietly in the supine position. Five consecutive readings were obtained with each of the 5 instruments, the order of use being randomized for each individual subject. The size of BP cuff was comparable in all cases and the same arm was used in each subject. A maximum of 25 min elapsed between the first reading with the first machine and the final reading with the 5 th instrument. Pulse rate was determined by palpating the radial artery for $15 \mathrm{sec}$, all subjects being in sinus rhythm. All measurements were made by K.M. and the fifth phase diastolic was used.

The internal consistency of each machine was determined by calculating the coefficient of variation (standard deviation divided by the mean and expressed as a percentage) for each variable measured 
TABLE 1. Capability and weight of the machines studied

\begin{tabular}{|c|c|c|c|c|c|c|}
\hline & Pulse rate & $\begin{array}{l}\text { Automatic } \\
\text { time setting }\end{array}$ & Print-out & $\begin{array}{l}\text { Variable } \\
\text { bleed rate }\end{array}$ & $\begin{array}{l}\text { Interface } \\
\text { with multi- } \\
\text { channel } \\
\text { recorders }\end{array}$ & $\begin{array}{c}\text { Weight } \\
\text { (kg) }\end{array}$ \\
\hline $\begin{array}{l}\text { Arteriosonde } 1225 \\
\text { Bosomat 11D } \\
\text { Elag Koln BE 237R } \\
\text { Omron HEM } 3\end{array}$ & $\begin{array}{l}\text { Yes } \\
\text { Yes } \\
\text { Yes } \\
\text { No }\end{array}$ & $\begin{array}{l}\text { Yes } \\
\text { Yes } \\
\text { No } \\
\text { No }\end{array}$ & $\begin{array}{l}* \\
\text { Yes } \\
\text { Yes } \\
\text { No }\end{array}$ & $\begin{array}{l}\text { Yes } \\
\text { Yes } \\
\text { No } \\
\text { No }\end{array}$ & $\begin{array}{l}\text { Yes } \\
\text { Yes } \\
\text { No } \\
\text { No }\end{array}$ & $\begin{array}{r}13 \cdot 9 \\
7 \cdot 9 \\
4 \cdot 5 \\
8 \cdot 5\end{array}$ \\
\hline
\end{tabular}

* Chart recorder available at additional cost.

in each subject. The averages of these coefficients of variation were then determined for each instrument. Comparison of the values recorded by each instrument was achieved by repeated measures analysis of variance using the U.C.L.A. BMDP77 statistical package on an ICL2976 computer.

\section{Results}

The capability and weight of each machine are shown in Table 1.

TABLE 2. Coefficients of variation for the machines

\begin{tabular}{lccc}
\hline & Systolic & Diastolic & $\begin{array}{c}\text { Pulse } \\
\text { rate }\end{array}$ \\
\hline Random Zero & $3 \cdot 1$ & $4 \cdot 5$ & 6 \\
Arteriosonde 1225 & $3 \cdot 5$ & $5 \cdot 9$ & 8 \\
Bosomat 11D & $2 \cdot 8$ & 3.9 & $5 \cdot 6$ \\
Elag Koln BE 237R & 2.9 & $5 \cdot 1$ & $7 \cdot 7$ \\
Omron HEM 3 & $3 \cdot 1$ & $5 \cdot 6$ & - \\
\hline
\end{tabular}

The coefficients of variation for each machine are shown in Table 2. It is clear that there is a high degree of internal consistency for each of the various forms of measurement.

The range of systolic pressure in the subjects studied was $106-179 \mathrm{mmHg}$ as determined by the Random Zero Sphygmomanometer. The mean data generated for this population by each machine are

TABLE 3. Mean BP and pulse rate data (18 subjects)

\begin{tabular}{lccc}
\hline & (a) & (b) & (c) Pulse rate \\
\hline Random Zero & 141.7 & 97.3 & 69 \\
Arteriosonde 1225 & 131.6 & 90.6 & 70.5 \\
Bosomat 11D & 140.5 & 97.2 & 69 \\
Elag Koln BE 237R & 138.8 & 93.8 & 70 \\
Omron HEM 3 & 138.9 & 95.1 & - \\
\hline & $\mathrm{F}=5.74$ & $\mathrm{~F}=5.34$ & $\mathrm{~F}=0.51$ \\
& $P=0.001$ & $P=0.001$ & $P=0.7$
\end{tabular}

shown in Table 3(a). The significant difference between the results obtained is attributable only to the values recorded by the Arteriosonde.
The range of diastolic pressure as determined by the Random Zero Sphygmomanometer in these subjects was $68-138 \mathrm{mmHg}$. The mean data generated for the same population by each machine are shown in Table 3(b). Again the significant difference between the readings is attributable to the Arteriosonde.

The values determined for heart rate are shown in Table 3(c). Heart rate ranged from 61 to 92 beats $/ \mathrm{min}$ and no significant difference exists between the various forms of measurement.

There was an 8-fold difference in price between the machines studied. Cheapest was the Elag Koln BE 237R which currently (1980) costs $£ 595$ (excluding tax) while the Arteriosonde 1225 commands a price of $£ 4,888$. A chart recorder for the Arterio sonde adds considerably to this cost. The Bosomat. 11D provides the same range of technical capability as the Arteriosonde 1225 and costs $£ 1,850$. The Omron HEM 3 was slightly more expensive than the Elag while having fewer facilities.

Each machine was portable, although the weight of the Arteriosonde 1225, even without a chart recorder (Table 1), required the use of a trolley. The cuffs of machines using microphonic detection were easy to apply but that of the Arteriosonde required somewhat greater care and experience.

\section{Discussion}

The machines tested were chosen because their range of capability and price is representative of the automated BP machines currently available. The study was designed to compare these various machines with each other, to compare each of the machines with a widely used standard method of $I$ BP measurement and to assess practical strengths or weaknesses of the various machines. It was not $N$ the authors' intention to determine the extent to $N$ which the various readings approximate intraarterial pressure measurements.

Each of the machines studied demonstrated a highly satisfactory degree of internal consistency. However, when comparisons between machines were made it was clear that the Arteriosonde 1225 consistently recorded both systolic and diastolic 
pressures which were below those determined by the mercury sphygmomanometer and the other automated machines. The systolic and diastolic values determined with the other 3 automated machines did not differ significantly from the results obtained with the Random Zero Mercury Sphygmomanometer. These findings are not altogether surprising in that the Arteriosonde determines BP by an ultrasonic technique while the other 3 automated machines have in common a microphonic system of blood pressure determination which is essentially the same as that used during manual recordings. However, 2 important points should clearly be made. First, there is considerable interest in using automated BP recorders for various epidemiological investigations. The results obtained in these studies will inevitably be compared with previous data which were exclusively generated by the use of mercury sphygmomanometers. If comparability between studies is to be maintained then it would seem imperative to use an automated BP recorder producing results which are themselves comparable with those obtained using a mercury sphygmomanometer. Second, if more than one type of automated BP recorder is available for use in a research study, then it would be important to use the same type of machine throughout since a change between the Arteriosonde and one of the other forms of recording could result in artificially different pressure readings.

From the practical standpoint, there was a clear difference in the extent to which the various machines were portable and this is reflected in the range of weight shown in Table 1. For research purposes it is often desirable to interface a BP recorder with a multi-channel machine or to make readings at predetermined intervals and only the 2 most expensive machines investigated (Arteriosonde 1225 and Bosomat 11D) had these capabilities. However, if requirements do not extend beyond the reliable recording of $\mathrm{BP}$ and heart rate using portable equipment, the considerable expense of these machines would be difficult to justify.

\section{Acknowledgments}

We wish to acknowledge the valuable statistical assistance of Dr David Sumner. This study was supported in part by a British Heart Foundation Research Fellowship (BHF806) to P.C.R. 